\title{
Development of clinical judgment model to guide nursing interns
}

\author{
Azza Fathi Ibrahim*1, Azza Anwar Aly², Magda Atiya Gaber ${ }^{3}$ \\ ${ }^{1}$ Nursing Education Department, Faculty of Nursing, Alexandria University, Egypt \\ ${ }^{2}$ Medical-Surgical Nursing Department, Faculty of Nursing, Damanhur University, Egypt \\ ${ }^{3}$ Department of Nursing Administration, Faculty of Nursing, Zagazig University, Egypt
}

Received: February 8, 2018

DOI: $10.5430 / \mathrm{cns} . v 6 \mathrm{n} 4 \mathrm{p} 1$
Accepted: April 7, 2018

Online Published: April 16, 2018

\begin{abstract}
Every day and every moment, nurses have to deal with a wide variety of patient's issues and problems, with multiple difficulties and conflicts. Nurse's judgment considers the core component of healthcare activities. This judgment directs her/his achievement and choices, not for her/him only, but for other healthcare professionals. Thus, nurses have to be competent observers and decision makers with reasoning and sound regarding their intervention and practice. Clinical judgment skills are essential aptitudes in nursing practice, predominantly, in nursing internship intermediary period, in which, a graduate nurse faced several predicaments and obstacles in such transitory experience from academic work to real labor. The present study aimed to develop a clinical judgment model to guide nursing interns in their nursing practice and assess its effectiveness on nursing interns' clinical judgment knowledge and skills. The study passed through Quasi-experimental pretest-posttest research design. A stratified random sampling approach was used to recruit 50 nursing interns as an experimental group out of 305 . The collection of data was carried out in the following hospitals of nurses' intern's training: Damanhur Medical National Institute, El Raee El Saleh, El Farok and Kafer El Dawar Hospitals, in Damanhur, Egypt. The Clinical Judgment Evaluation Sheet (CJES) was employed to collect necessary data. It included two parts: the Clinical Judgment Knowledge Test that was developed by Fathi \& Aly in 2018, beside the Lasater Clinical Judgment Rubric (LCJR) that was developed by Kathie Lasater et al., in 2009. Results before using the developed model demonstrated that there were observed lacking in knowledge and skills about clinical judgment in nursing practice among experimental group. Then improvements were noticed after using the developed clinical judgment model. These results confirm that the use of an educational and self-learning reference such as the developed clinical judgment model is a successful tool for Egyptian nursing interns in nursing practice. Conclusion and recommendations: There is an understandable deficiency of nursing interns' clinical judgment knowledge and skills in nursing practice. But, after using the developed clinical judgment model with them as a self-learning reference, it was confirmed that it is a helpful approach to develop and improve clinical judgment knowledge and skills of nursing interns. Creativity in using instructional aides and self-learning approaches is an essential ability that is important among nurse educators and preceptors who direct nursing intern's performance. For further sturdies, replicate the study using the developed model with different subjects in nursing practice or develop new instructive models about creative, reflective, discovery, and decision-making models among nursing interns.
\end{abstract}

Key Words: Clinical judgment, Model, Nursing interns

*Correspondence: Azza Fathi Ibrahim; Email: azza_fathy2008@yahoo.com; Address: Nursing Education Department, Faculty of Nursing, Alexandria University, Egypt. 


\section{INTRODUCTION}

Nursing care activities are the heart of healthcare system. Its high quality is a necessitate requirement for attaining acceptable patients' outcomes. Nurses are confronting a variety of challenging experiences which need appropriate clinical talents. Clinical judgment capabilities are essential skills that should be learned and used by professional nurses, especially in internship period. However, nursing interns still have an inadequacy of such skills. ${ }^{[1-3]}$ Clinical judgment is important intellectual and performance potentialities which are including the ability to examine and recognize, comprehend and deduce, and to decide proper care responses. Accordingly, these skills are healthcare management activities and valuable nursing capabilities for professional nurses and particularly with nursing interns. ${ }^{[4,5]}$

Further, clinical judgment permits the nurse to correlate the information parts to determine them, to find bonds with recognized facts, and to explore and understand the present data with logical justification. Clinical judgment skills help nurses, especially in field experience, to discover, connect and deduce the clinical picture of the disease for a given patients situation. The nurse cannot understand each piece of information separately without integration between each meaning of this information, this way of thinking may disturb the nurse behaviors and decisions. But when all information parts are integrated and recognized as a whole logically, the nurse can easily reach a judgment. ${ }^{[3,4,6]}$

The internship year is the first chance for graduate nurses to have contact with the responsibilities of clinical performance. It is called field experience that in one training year period which is after the academic studying years. Nursing faculty evaluates this period, and the graduate's students cannot obtain their bachelor certificate without this clinical year. It is a critical time and transient training instance in which the new graduates confront the real work challenges. Therefore, nursing interns have intense requisites of training and learning about clinical judgment skills that can be done through their preceptors. Graduates at this time have multiple stressors and tasks which may be related to their inadequate knowledge and skills of the real clinical work. Accordingly, in Egypt, clinical judgment is the most subtle nursing skills that are very important to be acquired by nursing interns. ${ }^{[6-9]}$

Clinical judgment can be taught and learned by several strategies and tools such as interactive lectures, role-playing with scenarios, simulations and educational models. Moreover, nursing interns have to use many self-learning tools such as booklets, flyers or models to help them in observing, adjusting, performing and changing their behaviors to competent ones. At the same time, nurse preceptors should develop, create and use those teaching tools for guiding interns in assessment, planning, practicing, evaluating and documenting nursing activities. ${ }^{[5,10,11]}$

A teaching model is an approach to clarify and present phenomena and issues with sound, reasonable and logical illustrations and simplify the recognized relationship between concept components. A nursing model is frequently explained as "a representation of reality or a more simple way of organizing a complex phenomenon". It is a consolidation of both concepts and assumptions that combines them into a meaningful arrangement. ${ }^{[9,12]}$ Furthermore, a teaching model is considered as a strategy and tool for establishing a self-reference source and guidance for self-learning and thus fosters self-awareness and learning. When using such learning tools, the healthcare professionals can be competent in their healthcare practice. Additionally, educational models can serve to promote self-competency in the development of clinical judgment skills which is essential for nursing interns. ${ }^{[11,12]}$

\subsection{Theoretical framework}

Nursing interns have to deal with a broad range of issues related to the condition of each patient including signs, symptoms, investigations, complications, and improvements as well as explanations of clinical records and communication with physicians or peers. Therefore, the nursing intern's judgment is at the heart of care delivery. ${ }^{[5,8,12]}$

Based on Lasater's work in 2009, clinical judgment in itself encompasses a cycle of sensory activities which begins with perceptions and which is followed by cognitive processing associated with the interpretation of information through the mental operations of reasoning and judgment. Beyond observation, clinical judgment allows the nurse intern to associate pieces of information, review them, establish relationships with known facts, and analyze and interpret the data at hand from both a critical and rational perspective. The following diagram clarifies the clinical judgment model that was developed by Tanner, 2006, and which was a base for clinical judgment rubric measurement by Lasater in 2009 (see Figure 1)..$^{[5,8,13]}$

Based on the previous theoretical framework and the needs of nursing interns, the researchers developed a clinical judgment model. A model is a new learning tool including more detailed behaviors that guide the nursing interns in their clinical judgment phases at their nursing work. But at the same time, it has grassroots foundations from the thorough review of the related literature. ${ }^{[1,3-5,11,13-16]}$ It can be operationally defined as a representative diagram that clarifies sensory and observational skills as well as the intellectual skills of re- 
flection, reasoning and critical thinking that allows the nurse intern to exercise genuine clinical judgment and develop a rational in care decisions. The developed model represented the four phases of clinical judgment skills in detailing sequential behaviors which provided clear directions for care interventions and justified the relationship between phases of the judicial process.

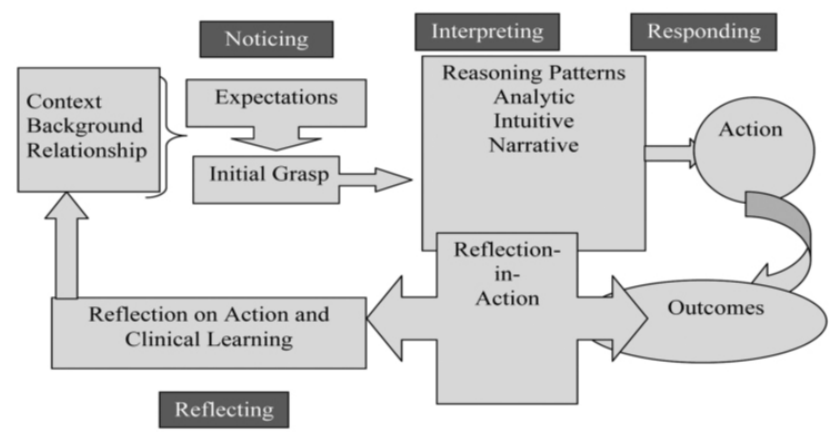

Figure 1. Clinical judgment model ${ }^{[4]}$

\subsection{The significance of the study}

There is an understandable deficiency of nursing interns' clinical judgment knowledge and skills in nursing practice, while, clinical judgment in nursing practice is a significant educational requirement, particularly in the internship period. In Egypt, nursing interns have been assessed for their clinical judgment knowledge and skills, and in the same time they were instructed by some of the previous clinical judgment models (such as Tanner model), they expressed no understanding of many points in the models, and then commented that they need details and clarifications. Their expression was due to that they found several concepts in the previous models such as analytical, intuitive reasoning or reflection on the action that was vague and need explanations. At the same time, they wanted to understand how to apply those concepts to definite cognitive and behavioral skills in nursing work. ${ }^{[14]}$ Therefore, the current study illustrated the importance to use of the self-learning tool, such as the developed Clinical Judgment Model, in real clinical situations among nurse interns, with enough details about clinical judgment process. Self-learning model should be taught and explained first to the nursing intern and clarified its integration in nursing practice, followed that the interns could use it in several clinical situations independently. As well, the current study presented the effect of this model on the clinical judgment knowledge and skills among nurse interns. Evidently, clinical judgment skills are important abilities which need to be learned by proper instructional aides such as self- referencing models. The Clinical Judgment Model will be a crucial and necessary guide to help nursing interns develop competent and valid clinical decisions.

Published by Sciedu Press
Therefore the current study aims to develop a clinical judgment model to guide nursing interns, and then, assess the effect of the developed model on their clinical judgment knowledge and skills.

\subsection{Research hypothesis}

The experimental group of nursing interns will have improvement in clinical judgment knowledge and skills scores after using the developed educational model.

\section{METHOD}

\subsection{Study design}

The study passed through Quasi-experimental pretestposttest research design.

\subsection{Sample and setting}

The study was conducted at the Faculty of Nursing, University of Damanhur, Egypt. The data was collected in nursing interns' field experience training hospitals; Damanhur Medical National Institute, El Raee El Saleh, El Farok and Kafer El Dawar Hospitals, Egypt. The nursing interns were selected from the following hospital sections; Medical, Surgical, Pediatric, Obstetric, Oncology and Kidney Dialysis.

The minimum sample size of 47 was estimated for the experimental group, which recommended and determined by an epidemiological statistical program using the Fishers' formula $\mathrm{z} 2 \mathrm{pq} / \mathrm{d} 2 \mathrm{~A}$. Therefore, stratified random sampling is used in the selection of the training departments of the nursing interns, that followed by a proportionate systematic random sampling which was employed inside each department by using the names' list of nursing interns. The final sample size was 50 nursing interns out of total invited 305 interns from the mentioned settings. The selected nursing interns were recruited according to the following inclusion criteria (from both sexes, accepted participation in the study by signing a written informed consent, have experience in dealing with patient problems).

\subsection{Study tools}

For collecting the necessary data of the current study, the researchers used one tool:

Clinical Judgment Evaluation Sheet (CJES) involved two parts:

(1) Part I: Clinical Judgment Knowledge Test. which was developed by Fathi \& Ali in $2018^{[14]}$ to assess clinical judgment knowledge. It involved questions to identify the knowledge needs of nursing interns about clinical judgment concept, importance, and phases of nursing practice. Personal profile questions were involved. 
(2) Part II: Lasater Clinical Judgment Rubric (LCJR) which was developed by Kathie Lasater et al., in $2009^{[13]}$ to measure clinical judgment skills including noticing, interpreting, responding, and reflecting. Each phase was split into eleven skills with four rating scale: beginning $=1$, developing $=2$, accomplished $=3$, and exemplary $=4$. Forty-four is the maximum grading that represents good clinical judgment performance, and the minimal grading is fifteen that shows poor clinical judgment achievement.

Part I and II were adopted by the researchers. A pilot study was implemented on 12 nursing interns who were excluded from the study subjects, to investigate tool feasibility and necessary modifications were done. Tool validity was checked by a jury of nursing education, community nursing, medical-surgical nursing and nursing management department. For reliability, it was checked by Cronbach Alpha Reliability statistical test which approved $>0.7$ internal consistency.

\subsection{Ethical considerations}

The research protocol was proposed to the Faculty of Nursing, Damanhur University, and acceptance was obtained. Also, approvals to conduct the study were attained from the administration of the above settings, after detailed clarifying of the study purpose. Each nursing intern was interviewed and asked to sign a written informed consent on an individual basis. The interns were reassured for confidentiality, and there are no any penalties for internship evaluation related to the study process. They were reassured to withdraw at any point of the research time. The study passed in the following phases.

\subsection{Assessment phase: (before using the developed model)}

By structured interview, the researchers and the experimental group completed part I of the study tool. The researchers preferred to conduct the interview method, to support the nurse interns and explore their comments, thinking, expressions and attitudes that may provide a key justification for nursing interns' observable behavior in part II of the study tool.

For part II, the researchers applied structured observation using Part II of the study tool, on an individualized basis.

Nursing interns were instructed to deal with all clinical situations freely without any tension.

At the beginning of the interview, the researchers let the experimental group filling the personal profile, and by discussion, they completed part I of the study tool.

4
The experimental group was left to manage patient problems clinically in the attendance of the researchers who observed their clinical judgment skills (using study tool Part II) on an individual basis. The researcher kept being an only objective translator to the intern's behaviors. The researcher committed to use study tool part II to meet study aim.

Common patients' complains were detected and managed by the nursing intern were: vomiting, skin ulcer, hyperglycemia, vertebral pain, wound care, urinary complaints, delivery bleeding, pediatric respiratory distress, fever, diarrhea, dialysis shunt problems, health education needs about medication.

The common nursing interventions taken by the nursing interns are pain management, vomiting care, physician and management consultation, oxygen therapy, providing insulin therapy, and providing health education sessions.

The researchers allowed each nursing intern in the experimental group to document all cognitive and psychomotor performance, for each clinical judgment phase: noticing, interpreting, responding and reflecting. Examples of such data were: type of patient complaints, the criteria, and evidence on a patient that denoted the related patient's problems, understanding, and interpretation of patient data. Other examples of such data: what is behind patient data, the association between the collected data and scientific views, priorities of care, management plan, steps of care given, communication manner, ethical concerns, care outcome and patient response. Plus nursing intern self-evaluation, and the data for improvement (all needed facilities were given such as care equipment and paper and pens for documentation). All nurses' intern's documentation were collected to complete filling of the LCJR.

In the same time, the researcher kept documenting all behaviors of the nursing interns in each LCJR phases. For each intern, the researchers investigated what she documented and what the nurse intern documented in each clinical judgment phase, then summarizing all observable behaviors with the documented interpretation and justifications of the interns plus the patient's data. Next, the researcher analyzed the relationship between the nursing interns' clinical judgment observable behaviors and their documented data, particularly for their justifications and completion of these data for each clinical judgment phase. According to each clinical judgment phase, the skills performance grading was estimated for each phase that followed by estimation of the total grading of whole LCJR performance.

The experimental group was allowed adequate time to do their care interventions with patients. (Observation lasted for 2-3 hours, using LCJR in morning or evening shifts).

ISSN 2324-7940 E-ISSN 2324-7959 
All extrinsic factors were controlled such as interruptions, developed model.

patients' relative's visits, and peer communications.

\subsection{Clinical judgment model development phase}

According to the revealed data from the Fathi \& Ali's work in $2018,{ }^{[14]}$ and extensive and comprehensive literature review, ${ }^{[1,3,4,11,13,15,16]}$ the Clinical Judgment Model, was developed including the four aspects of clinical judgment skills. The model content provided a simple presentation of the clinical judgment concept and its phase's details to reach suitable clinical decisions. It also clarified detailed actions and some illustrations regarding clinical judgment component relationships.

Colors and arrows were used for organization and attractiveness with a value for the concept clarifications of clinical judgment.

The model content was adjusted by a jury of seven experts in medical-surgical, community nursing, administration, and nursing education fields to ensure its content validity. The jury investigated the composition of the model for frame, attractiveness, organization, clarity and concept meaning with clear structures. The jury decided that the model content covered all clinical judgment skills and educational domains. Furthermore, the jury described to which extent the model was supported by evidence and theoretical background including illustrations, knowledge, and descriptive cognitive skills that could be done by the nurse intern. Also, the model was provided to 10 of nursing interns who apart from the study sample, to check its feasibility and all modifications were done.

The developed model consisted a simple diagram that is representing the four phases of clinical judgment: Noticing, Interpreting, Responding and Reflecting. Each phase is followed by some explanation of performance skills that required. Furthermore, each group of skills in each phase followed by a group of knowledge items that needed for achieving each skill. After each group of knowledge, the acceptable results of nurses' performance in each phase are clarified. Arrows and frames for each piece of data are used to provide more understanding and clarifying of phase's relationships and the results of each phase. Clinical judgment model in nursing practice is considering an organized purposeful and clear representation of clinical judgment process that is used to describe and explain it that cannot be experienced directly. Models are central to what scientists do, both in their research as well as when communicating their explanations in clinical practice. Critical thinking and problem solving, decision making and creativity skills are the basic behaviors to be applied by nurse interns through this

\subsection{Experiment phase}

The experimental group was instructed to use the developed Clinical Judgment Model with patients in any clinical area or clinical situation at the mentioned settings. They were instructed by discussion, role play, and flip chart teaching methods for two hours about the developed clinical judgment model on an individual basis. The interns were let to apply this model to their patients for two weeks.

The developed model was left with the nurse intern as a selfreferencing tool that allows him/her to return to its data or put it in the nursing station as a reference for all staff. After researcher clarification and instructions, the nurse intern can use the development very easy and return to it at any time for guidance.

The researchers kept in contact with the experimental group of nurse interns every two days by telephone or by interviews to ensure their utilization of the developed model. Any clarifications, explanations, and examples were given to them about the developed model.

Gifts and presents in the form of watches, lunch meals, handbags and lab coats were given to the nurse interns as a source of learning motivation and enhancing their cooperation.

After the two weeks, the researchers reassessed again the clinical judgment knowledge and skills among the experimental group using the study tool (Parts I \& II).

\subsection{Evaluation phase}

The scores of the experimental group knowledge test and LCJR scores were compared for each nurse intern before and after using the developed model. Then the difference was estimated to determine the effect of the developed model.

For the statistical analysis, the data was organized, computerized, tabulated and analyzed by using quantitative and qualitative approaches.

Data collection period lasted from May 2017 to August 2017.

\subsection{Data analysis}

The data from the experimental group was gathered, prepared, computerized, coded, analyzed and tabulated. Statistical Packages for the Social Sciences (SPSS), Version 20.0 for Windows, and Microsoft Excel Spread Sheet Package (Office 2010) were used for result analysis of the study. For descriptive analysis, the mean, standard deviation, percentage, and frequency were used. Chi-square, $T$-test and $p$-values were used for analytical statistics and to clarify the significance before and after use of the developed model. The qualitative 
data that collected during nursing intern's observation and investigation of their documents were translated to grades and calculated into the LCJR grading.

\section{Results}

\section{Nursing interns' profile}

Table 1 clarifies that about more than one half of the experimental group (54\%) were in their early twenties, and most of them $(72 \%)$ were females. As well, the majority of them $(76 \%)$ came from rural areas, while about one-third (36\%) were not yet married. Exactly one half of the experimental group $(22 \%, 28 \%)$ had their internship clinical training in Medical and Oncology nursing. About one half of experimental group $(24 \%, 20 \%)$ had previous work experience time ranging from 5 to 10 months. All interns in the experimental group $(100 \%)$ were in direct contact with patients. About two-thirds of them $(64 \%)$ reported that they were never used self-learning references before.

Table 2 shows a comparison before and after use of the developed model among the experimental group for their knowledge about the concept of clinical judgment in nursing practice. It is obvious that there is a significant improvement in the entire experimental group before and after implementation of the developed clinical judgment model regarding all elements of the concept of clinical judgment. Before using the developed model, it is clear that the experimental group had a serious lack of such knowledge elements. Therefore, only $10 \%$ of the experimental group identified the clinical judgment definition. However, after using the model, their percentage reached $84 \%$. Moreover, no one and a minimal percent of the experimental group $(0.00 \% \& 24 \%)$ used and valued the clinical judgment in nursing practice before implementing the developed model. But after using it, $56 \%$ \& $80 \%$ of them always use and recognize the importance of the clinical judgment in their practice. Remarkably, improvement happened before and after using the developed model, concerning intern awareness regarding needed basic skills to practice clinical judgment in nursing practice $(0.00 \%$ \& $14 \%$ vs. $28 \%$ \& $58 \%$ ). As well, in mentioning an example of clinical judgment in nursing practice, $4 \%$ vs. $92 \%$ clarified the interns' progress before and after using the developed model. Respectfully, before implementing the developed model, a very minimal proportion of the experimental group (4\%) viewed that prior training is required for clinical judgment utilization, but after using the developed model, this percent became $92 \%$. There is an observed improvement in interns' knowledge about the concept of clinical judgment in nursing practice after using the developed model, $p=.000$.
Table 1. Nursing interns' profile as presented by number and percentage

\begin{tabular}{|c|c|c|}
\hline \multirow{2}{*}{ Participants profile } & \multicolumn{2}{|c|}{ Experimental Group $(\mathrm{N}=\mathbf{5 0})$} \\
\hline & No. & $\%$ \\
\hline \multicolumn{3}{|l|}{ Age } \\
\hline - 22 - 24 & 27 & 54 \\
\hline - $25-27$ & 23 & 46 \\
\hline \multicolumn{3}{|l|}{ Sex } \\
\hline - Male & 14 & 28 \\
\hline - Female & 36 & 72 \\
\hline \multicolumn{3}{|l|}{ Residence } \\
\hline - Rural & 38 & 76 \\
\hline - Urban & 12 & 24 \\
\hline \multicolumn{3}{|l|}{ Marital status } \\
\hline - Single & 18 & 36 \\
\hline - Married & 30 & 60 \\
\hline - Divorce & 2 & 4 \\
\hline - Widowed & 0 & 0.00 \\
\hline \multicolumn{3}{|l|}{ Intern specialties } \\
\hline - Medical Nursing & 11 & 22 \\
\hline - Surgical Nursing & 6 & 12 \\
\hline - Pediatric Nursing & 8 & 16 \\
\hline - Obstetric Nursing & 6 & 12 \\
\hline - Oncology Nursing & 14 & 28 \\
\hline - Kidney dialysis & 5 & 10 \\
\hline \multicolumn{3}{|l|}{ Intern training duration } \\
\hline - None & 6 & 12 \\
\hline - One month & 9 & 18 \\
\hline - 2-4 months & 8 & 16 \\
\hline - 5-7 months & 12 & 24 \\
\hline - 8-10 months & 10 & 20 \\
\hline - $11-12$ months & 5 & 10 \\
\hline \multicolumn{3}{|c|}{ Direct interaction with patients } \\
\hline - Yes & 50 & 100.00 \\
\hline - No & 0 & 0.00 \\
\hline \multicolumn{3}{|c|}{ Using self-learning references } \\
\hline - Yes & 18 & 36 \\
\hline • No & 32 & 64 \\
\hline
\end{tabular}

Table 3 reveals the comparison before and after use of the developed model among the experimental group regarding their knowledge about the clinical judgment phases in nursing practice. For the noticing phase, it is apparent that there was a STRONG statistically significant difference before and after using the developed model. This significant difference was about meaning, knowledge components and nurses' target from the noticing phase $(15 \%$ vs. $84 \%, 8 \%$ vs. $86 \%$ \& $10 \%$ vs. $94 \%$ ). Similarly, for the interpreting phase, it was $14 \%$ vs. $90 \%, 14 \%$ vs. $64 \%$ and $6 \%$ vs. $90 \%$. As well, for the responding phase, the responses were $20 \%$ vs. $94 \%$, $14 \%$ vs. $88 \%$ \& $26 \%$ vs. $94 \%$. Likewise and finally for the reflecting phase, the results showed $14 \%$ vs. $84 \%, 6 \%$ vs. 
$84 \%$ and $24 \%$ vs. $96 \%$, and $p=.000$.

Table 4 illustrates the difference before and after using the developed model by the experimental group about their observed clinical judgment skills in nursing practice. It is obvious that there is a great improvement in the nursing intern' clinical judgment skills in nursing practice before and after using the developed model. Before using the developed model, the mean values in all clinical judgment phases were below a score of two, but after using the developed model, the mean values increased to be above three in all clinical judgment phases (noticing, interpreting, responding and reflecting). For the noticing skills, the nursing interns had a mean score of four in seeking information after using the model. Also, in interpreting skills, they obtained a mean score of 4 in prioritizing data after implementing the developed model. Concerning responding skills, the nursing interns gained a mean score of 4 in their clear communication after applying the developed model. Finally, in reflecting skills, the experimental group achieved great progress before and after using the developed model by having mean score values above three and a half. Apparently, the experimental group achieved an observed improvement in their clinical judgment skills after implementation of the developed clinical judgment model.

Table 2. Nursing interns' knowledge about the concept of clinical judgment in nursing practice before and after using the developed model as presented by number and percent

\begin{tabular}{|c|c|c|c|c|c|c|}
\hline \multirow{3}{*}{$\begin{array}{l}\text { Knowledge related to the concept of clinical judgment } \\
\text { indent }\end{array}$} & \multicolumn{4}{|c|}{ Experimental Group $(\mathrm{N}=\mathbf{5 0})$} & \multirow{3}{*}{$\begin{array}{l}\text { Test of } \\
\text { Significant }\left(\chi^{2}\right)\end{array}$} & \multirow{3}{*}{$p$-value } \\
\hline & \multicolumn{2}{|c|}{ Before } & \multicolumn{2}{|c|}{ After } & & \\
\hline & No. & $\%$ & No. & $\%$ & & \\
\hline Meaning of clinical judgment & & & & & 54.958 & $<.001^{* * *}$ \\
\hline - Know & 5 & 10 & 42 & 84 & & \\
\hline - Didn't know & 45 & 90 & 8 & 16 & & \\
\hline Use clinical judgment in nursing practice & & & & & 60.593 & $<.001^{* * *}$ \\
\hline - Always & 0 & 0.00 & 28 & 56 & & \\
\hline - Sometimes & 4 & 8 & 14 & 28 & & \\
\hline - Rarely & 22 & 44 & 5 & 10 & & \\
\hline - Never & 24 & 48 & 3 & 6 & & \\
\hline Clinical judgment in nursing practice is important & & & & & 32.230 & $<.001^{* * *}$ \\
\hline - Always & 12 & 24 & 40 & 80 & & \\
\hline - Sometimes & 35 & 70 & 8 & 16 & & \\
\hline - Rarely & 3 & 6 & 2 & 4 & & \\
\hline - Never & 0 & 00.0 & 0 & 0.00 & & \\
\hline Nurses' basic skills needed to practice clinical $\downarrow$ & & & & & 61.891 & $<.001^{* * *}$ \\
\hline - Careful and accurate observation \& attention & 13 & 26 & 2 & 4.2 & & \\
\hline $\begin{array}{l}\text { - Intellectual processing (integrate pieces of empirical \& } \\
\text { conceptual information) }\end{array}$ & 10 & 20 & 1 & 2.1 & & \\
\hline $\begin{array}{l}\text { - Analysis \& reorganization the aspects of a given } \\
\text { situation }\end{array}$ & 6 & 12 & 1 & 2.1 & & \\
\hline - Reasoning \& interpretation & 8 & 16 & 0 & 0 & & \\
\hline - Summarization with conclusion \& logical deduction & 6 & 12 & 1 & 2.1 & & \\
\hline - Selection of 2 or 3 answers from the above & 7 & 14 & 14 & 29.2 & & \\
\hline - Selection of all of the above. & 0 & 0.00 & 29 & 60.3 & & \\
\hline \multirow{2}{*}{ Mention an example of clinical judgment } & 2 & 4 & 46 & 92 & 77.564 & $<.001^{* * *}$ \\
\hline & 48 & 96 & 4 & 8 & & \\
\hline Prior training is required for clinical judgment & & & & & 77.564 & $<.001^{* * *}$ \\
\hline - Yes & 2 & 4 & 46 & 92 & & \\
\hline - No & 48 & 96 & 4 & 8 & & \\
\hline
\end{tabular}


Table 3. Nursing interns' knowledge about the clinical judgment phases in nursing practice before and after using the developed model as presented by number and percent

\begin{tabular}{|c|c|c|c|c|c|c|}
\hline \multirow{3}{*}{ Knowledge related to clinical judgment phases in nursing practice } & \multicolumn{4}{|c|}{ The experimental group $(\mathrm{N}=50)$} & \multirow{3}{*}{$\begin{array}{l}\text { Test of } \\
\text { Significant }\left(\chi^{2}\right)\end{array}$} & \multirow{3}{*}{$p$-value } \\
\hline & \multicolumn{2}{|c|}{ Before } & \multicolumn{2}{|c|}{ Before } & & \\
\hline & No. & $\%$ & No. & $\%$ & & \\
\hline \multicolumn{7}{|l|}{ Noticing phase } \\
\hline Meaning of noticing & & & & & 29.743 & $<.001^{* * *}$ \\
\hline - Careful observation of objective and subjective data in a clinical patient situation & 15 & 30 & 42 & 84 & & \\
\hline - Wrong answer & 35 & 70 & 8 & 16 & & \\
\hline Components of noticing knowledge needed $\downarrow$ & & & & & 65.437 & $<.001^{* * *}$ \\
\hline - Conceptual knowledge (the theoretical basis of the situation) & 22 & 44 & 1 & 2 & & \\
\hline - Background \& experience of the nurse & 7 & 14 & 2 & 4 & & \\
\hline - Nurse's relationship with the patient & 5 & 10 & 2 & 4 & & \\
\hline - Clinical context of care & 6 & 12 & 0 & 0.00 & & \\
\hline - Selection of 2 or 3 answers from the above & 1 & 8 & 16 & 32 & & \\
\hline - Selection of all of the above & 0 & 0.00 & 27 & 54 & & \\
\hline Nurses' target from noticing & & & & & 70.673 & $<.001^{* * *}$ \\
\hline - Wrong answer & 45 & 90 & 3 & 6 & & \\
\hline \multicolumn{7}{|l|}{ Interpreting phase } \\
\hline \multicolumn{7}{|l|}{ Meaning of interpreting } \\
\hline - Assembling data to understand and make sense & 7 & 14 & 45 & 90 & 57.853 & $<.001^{* * *}$ \\
\hline - Wrong answer & 43 & 86 & 5 & 10 & & \\
\hline Components of interpreting knowledge needed $\downarrow$ & & & & & 54.402 & $<.001^{* * *}$ \\
\hline - Using the particular useful patient data & 10 & 20 & 2 & 4 & & \\
\hline - Theoretical data & 13 & 26 & 3 & 6 & & \\
\hline - Experiential knowledge & 10 & 20 & 1 & 2 & & \\
\hline - Mix the three previous data to make sense & 10 & 20 & 2 & 4 & & \\
\hline - Selection of 2 or 3 answers from the above & 6 & 12 & 10 & 20 & & \\
\hline - Selection of all of the above & 1 & 2 & 32 & 64 & & \\
\hline Nurses' target from interpreting & & & & & 70.673 & $<.001^{* * *}$ \\
\hline - Develop a plan for patients' interventions with suitable clinical decisions. & 3 & 6 & 45 & 90 & & \\
\hline - Wrong answer & 47 & 94 & 5 & 10 & & \\
\hline - Wrong answer & 10 & 20 & 47 & 94 & & \\
\hline Components of responding knowledge needed & & & & & 64.821 & $<.001^{* * *}$ \\
\hline - Skills \& procedures knowledge & 5 & 10 & 2 & 4 & & \\
\hline - Self-efficacy skills knowledge & 18 & 36 & 3 & 6 & & \\
\hline - Anticipated patients responses & 7 & 14 & 0 & 0.00 & & \\
\hline - Art of communication and human relations & 6 & 12 & 1 & 2 & & \\
\hline - Anticipated ethical behaviors & 7 & 14 & 0 & 0.00 & & \\
\hline - Selection of 2 or 3 answers from the above & 7 & 14 & 9 & 18 & & \\
\hline - Selection of all of the above & 0 & 0.00 & 35 & 70 & & \\
\hline Nurses' target from responding & & & & & 48.167 & $<.001^{* * *}$ \\
\hline - Shows mastery of necessary nursing skills & 13 & 26 & 47 & 94 & & \\
\hline - Wrong answer & 37 & 74 & 3 & 6 & & \\
\hline \multicolumn{7}{|l|}{ Reflecting phase } \\
\hline Meaning of reflecting & & & & & 49.020 & $<.001^{* * *}$ \\
\hline - Judgment \& learning from experiences in real clinical time while care is occurring. & 7 & 14 & 42 & 84 & & \\
\hline - Didn't know & 43 & 86 & 8 & 16 & & \\
\hline \multicolumn{7}{|l|}{ Components of reflecting needed knowledge } \\
\hline - Data of self-evaluation about suitable selection from alternative interventions & 10 & 20 & 2 & 4 & & \\
\hline - knowledge of learning transfer availability & 6 & 12 & 1 & 2 & & \\
\hline - Patients' subjective \& objective data after interventions & 12 & 24 & 2 & 4 & & \\
\hline - Data of plan for improvement & 2 & 4 & 0 & 0.00 & & \\
\hline - Data to involve family and care team in the care plan & 2 & 4 & 2 & 0.00 & & \\
\hline - Overall implementation effectiveness data & 15 & 30 & 3 & 6 & & \\
\hline - Selection of 2 or 3 answers from the above & 3 & 6 & 15 & 30 & & \\
\hline - Selection of all of the above & 0 & 0.00 & 27 & 54 & & \\
\hline \multicolumn{7}{|l|}{ Nurses' target from reflecting } \\
\hline - Meet patient's needs and solve his/her problems with high-quality care & 12 & 24 & 48 & 96 & & \\
\hline - Wrong answer & 38 & 76 & 2 & 4 & & \\
\hline
\end{tabular}

Note. $=$ interns allowed to select more than one alternatives; ${ }^{* * *} p \leq .001$ 
Figure 2 clarifies the significant difference before and after using the developed Clinical Judgment Model among the experimental group of nursing interns. This difference was regarding knowledge about CJ concept, phases, and skills.
Obviously, there is a great improvement in nursing interns' CJ knowledge and skills after using this model. The developed Clinical Judgment Model confirms its effectiveness as an educational learning tool.

Table 4. Interns' clinical judgment skills in nursing practice among the experimental group before and after using the developed model as presented by means and standard deviations

\begin{tabular}{|c|c|c|c|c|c|c|}
\hline \multirow{3}{*}{ Lasater Clinical Judgment Rubric Items } & \multicolumn{4}{|c|}{ Experimental Group $(\mathbf{N}=\mathbf{5 0})$} & \multirow{3}{*}{$\begin{array}{l}\text { Test of Significant } \\
T \text {-test }\end{array}$} & \multirow{3}{*}{$p$-value } \\
\hline & \multicolumn{2}{|c|}{ Before } & \multicolumn{2}{|c|}{ Before } & & \\
\hline & Mean & SD & Mean & SD & & \\
\hline \multicolumn{7}{|l|}{ Noticing } \\
\hline - Focused observation & 1.13 & 0.67 & 3.22 & 0.65 & 15.8315 & $<.001^{* * *}$ \\
\hline - Recognizing deviations from expected patterns & 1.04 & 0.78 & 3.02 & 0.75 & 12.9387 & $<.001^{* * *}$ \\
\hline - Information seeking & 2.02 & 0.66 & 4 & 1.22 & 10.0936 & $<.001^{* * *}$ \\
\hline \multicolumn{7}{|l|}{ Interpreting } \\
\hline - Prioritizing data & 1.34 & 0.83 & 4 & 1.03 & 14.2191 & $<.001^{* * *}$ \\
\hline - Making sense of data & 2.00 & 0.47 & 3.04 & 0.66 & 9.0761 & $<.001^{* * *}$ \\
\hline \multicolumn{7}{|l|}{ Responding } \\
\hline - Calm, confident manner & 1.55 & 0.45 & 3.11 & 0.97 & 10.3160 & $<.001^{* * *}$ \\
\hline - Clear communication & 1.26 & 0.48 & 4 & 1.11 & 16.0209 & $<.001^{* * *}$ \\
\hline - Well-planned care with flexible intervention & 1.02 & 0.86 & 3.02 & 0.65 & 13.1188 & $<.001^{* * *}$ \\
\hline - Being skillful & 1.00 & 0.98 & 3.88 & 0.89 & 15.3833 & $<.001^{* * * *}$ \\
\hline \multicolumn{7}{|l|}{ Reflecting } \\
\hline - Evaluation/self-analysis & 1.35 & 0.87 & 3.66 & 0.76 & 14.1396 & $<.001^{* * *}$ \\
\hline - Commitment to improvement & 1.38 & 0.57 & 3.79 & 0.69 & 19.0408 & $<.001^{* * * *}$ \\
\hline
\end{tabular}

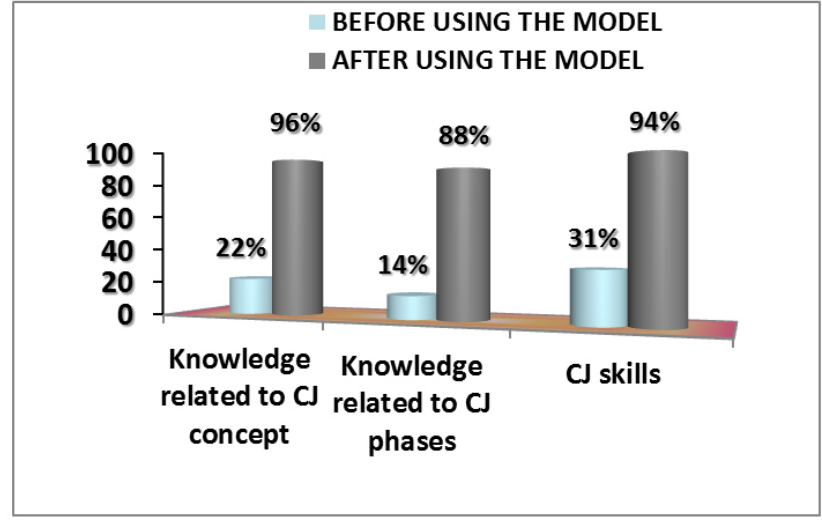

Figure 2. Mean percent before and after using the developed clinical judgment model as regards: clinical judgments' knowledge and skills among nursing interns in the experimental group

\section{Discussion}

Nursing interns have to manage several clinical and administrative duties, while they are facing the real challenges for the first time. Clinical judgment skills are the fundamentals that may help them in achieving the plan of patient care and implementing intervention with clear reasoning, justification, and decisions. ${ }^{[8,17,18]}$ But in many pieces of evidence, nurses have a series lacking in such vital skills in their practice. ${ }^{[4,8,14,15]}$ Therefore, it is necessary to help those nurses, mainly in critical time such as internship year, to obtain clinical judgment skills intellectually, behaviorally and professionally.

Self-learning aids and self-learning references are essential tools for supplementation and promotion of nurses' cognitive and practical or clinical achievement, especially with new graduates like nursing interns. They should be prepared and equipped with such aids as basic learning resources in nursing practice. Nurses will be competent managers and critical thinkers when they constantly learn and use self-learning tools such as diagram materials, maps, leaflets, handouts, announcements, and models which are essential instruments of nursing education references. ${ }^{[4,7,11,13]}$

In the current study, the experimental group proves that the use of simple diagrammatic self-learning tools, such as the developed clinical judgment model, can provide a drastic change in the knowledge and skills of nursing interns. This 
finding supports the study hypothesis which showed that the developed model as an instructional tool could influence the cognitive, affective, and psychomotor skills of nursing interns. The current experimental group's results revealed that after using the developed model, there was an obvious improvement in their knowledge about the concept and phases of clinical judgment in nursing practice. This result is supported by Ashcraft and Option, in 2012, who discussed the importance of the developed model by Tanner, in 2006, and clarified to which extent the model was a very effective tool in the illustration of a difficult concept such as clinical judgment in nursing practice. Models can represent theories, facts, concepts, principles, and phases in a very clear and understandable manner. They focus on the fact that the model is an instructional aide which helps educators to simplify any concept and guide learning transfer. ${ }^{[4,13,19]}$ Matching current findings, in nursing education, models are very effective instruments which are instructional means for excellent self-learning references for encouraging, comprehending, analyzing and concluding suitable care decisions. Moreover, models ensure that nurse graduates develop and apply their interventions in organized, sequential and measured approaches. ${ }^{[11,12,20]}$

Opposite to this result, clinical judgment is seen as an intangible concept that teachers find difficult to simplify and describe its phases. Some studies found that it is a complicated task to configure clinical judgment regarding the phases of noticing, interpreting, responding, and reflecting. ${ }^{[19,21]}$ However, this task can be possible, particularly with Egyptian nursing interns, because the current study confirms that and when the nursing educator has a deep understanding of the concept and can fragment it to be analyzed and easily evaluated; this concept can be easily learned.

Finally, about the comparison among the experimental group before and after using the developed model, the interns showed understandable progress and observed improvement in their clinical judgment skills after implementing the developed Clinical Judgment Model. Fitting this result, Niederhauser et al., 2012, illustrated that new educational instruments in nursing education are required to enhance graduates' preparation for the present healthcare changes. Clinical nursing education has an intense need to use models as clear, illustrative, simple, declarative and effective means which can explain clinical concept framework. Models in clinical nursing education are considered innovations in academic practice partnerships. ${ }^{[11,20,22]}$ Furthermore, the clinical training climate generates a powerful demand to develop new tools that help nurses apply their responsibilities in reality and encourages closing the gap between theory and practice. Integrating nursing information with learning experiences in patient conditions in a self-reference educational model will assist nursing interns to preserve learning enthusiasm and acquire clinical judgment skills. ${ }^{[4,8,23]}$ Without any doubt, educational models, such as the developed Clinical Judgment Model as a self-learning tool, are very effective approaches for acquiring knowledge, skills, and attitudes among nursing interns. The current study is exceptional in development, implementation, and evaluation of a clinical judgment developed self-learning model in real patient situations.

\section{Conclusions}

The current finding revealed that there was an obvious and serious lack in nurse interns' clinical judgment knowledge and skills in nursing practice in Egypt among experimental group. However, when using the developed Clinical Judgment Model with nursing interns as a self-learning reference, it was confirmed that this was a helpful approach to develop and improve nursing clinical judgment knowledge and skills. Nurse educators should initiate steps to develop such models for empowering her/his role in nursing education and practice. With the application of these educational models among nursing interns, they will be competent decision makers and cleverer professionals in the nursing field which will reflect positively on patient outcome and healthcare services at all.

\section{Recommendations and further studies}

In general, the major recommendations that derived from the current study are: Educational support should be implemented with nursing interns by various teaching methodologies. Instructed self-learning tools such as the developed clinical judgment model are very effective to enhance nursing interns' knowledge and skills in clinical practice and avoid using of multiple incentives to limit any coercion effect on participants learning. Furthermore, it is better to provide enough time to the interns or any learners as participants in studies, to apply the educational methodologies (more than two weeks) to observe the change in their knowledge and skills.

According to the current study findings, the following further studies should be implemented regarding nursing research, nursing education, and nursing practice. For nursing research: Replicate the study using the developed model with different subjects in nursing practice or develop new instructive models about creative, reflective, discovery, and decision-making models among nursing interns, but let them apply those models in longer time, more than one month and allow further second or third assessment after using the new model. Develop other assessment tools for measuring clinical judgment skills that would include descriptive criteria for nursing behaviors and their documents about justifications, 
communication, and ethical performance. Perform a study regarding the relationship between nursing intern clinical judgment skills \& patient outcome. Research on nursing intern perceptions is needed about clinical judgment skills and internship experience. For nursing education: Use different teaching and learning models for improving clinical judgment and decision making skills in undergraduate clinical training. For nursing practice: Use self-learning instructional references among registered nurses regarding clinical judgment. Establish a study of training clinical nurse educators and registered nurses on using clinical judgment model in real patient situations.

\section{CONFLICTS OF INTEREST DisClosure}

The authors declare they have no conflicts of interest.

\section{REFERENCES}

[1] Seacrist M, Noell D. Development of a Tool to Measure Nurse Clinical Judgment during Maternal Mortality Case Review. The Association of Women's Health, Obstetric and Neonatal Nurses. 2016; 45(6): 870. https://doi.org/10.1016/j.jogn.2016.03.143

[2] Oermann MH, Garvin MF. Stresses and Challenges for New Graduates in Hospitals. Nurse Education Today. 2002; 22: 225-230. PMid: 12027604. https://doi.org/10.1054/nedt.2001.0695

[3] Alfaro-LeFevre R. Critical thinking, clinical reasoning, and clinical judgment: a practical approach. 5th Ed. St. Louis, MO: Saunders Elsevier; 2012 PMid: 22416533.

[4] Tanner CA. Thinking like a nurse: A research-based model of clinical judgment in nursing. Journal of Nursing Education. 2006; 45: 204-211. PMid: 16780008.

[5] Lasater K. High fidelity simulation and the development of clinical judgment. Journal of Nursing Education. 2007; 46: 269-276. PMid: 17580739.

[6] Casey K, Fink R, Krugman M, et al. The Graduate Nurse Experience. Journal of Nursing Administration. 2004; 34(6): 303-311. PMid: 15190226. https://doi.org/10.1097/00005110-200 406000-00010

[7] Oermann MH, Garvin MF. Stresses and Challenges for New Graduates in Hospitals. Nurse Education Today. 2002; 22: 225-230. PMid: 12027604. https://doi.org/10.1054/nedt.2001.0695

[8] Abdel KAM, Mohamed EA, Abood SA. Perception of Nurse Interns about Clinical Assignment Preparation Requirements. Journal of American Science. 2012; 8(12): 676-682.

[9] Fathi A, Akel D, Fatah LAMAE, et al. Emotional intelligence and internet addiction among nursing interns. Clinical Nursing Studies. 2016; 4(1): 70-80. https://doi .org/10.5430/cns .v4n1p70

[10] Luctkar-Flude M, Baker C, Medves J, et al. Evaluating an interprofessional pediatrics educational module using simulation. Clinical Simulation in Nursing. 2013; 9(5): 163-169. https://doi.org/ 10.1016/j.ecns.2011.11.008

[11] Fathi A. Development of Patient Health Education Model to Guide Undergraduate Nursing Students. Unpublished MSN Thesis. Alexandria: the University of Alexandria, Faculty of Nursing. 2006; 23-37.
[12] Fathi A, Tawfik F, Abudari M. Using a self-care management tool to improve self-care and quality of life in patients with congestive heart failure. Clinical Nursing Studies. 2016; 4(3): 1-17. https://doi.org/10.5430/cns.v4n3p1

[13] Cato ML, Lasater K, Peeples AI. Nursing students' self-assessment of their simulation experiences. Nursing Education Perspectives. 2009; 30(2): 105-108. PMid: 19476075.

[14] Fathi A, Ali A. Clinical judgment among nursing intern. International Journal of Clinical Nursing Studies. 2018; 6(3): 19. https : //doi.org/10.5430/cns.v6n3p19

[15] Facione NC, Facione PA. "Critical Thinking and Clinical Judgment" from Critical Thinking and Clinical Reasoning in the Health Sciences: A Teaching Anthology. Insight Assessment/The California Academic Press: Millbrae CA; 2008. 1-13 p.

[16] Black P. Critical Thinking, the Nursing Process, and Clinical Judgment. Chapter 8. 2012; 171-192. PMid: 22721422. Available from: https://pdfs.semanticscholar.org/4bc5/06eed955 71fd129d36c6b3f3c887211c6317.pdf

[17] Yahiro K, Saylor A. A critical model for nursing judgment. Journal of Nursing Education. 1994; 33(8): 351-356.

[18] Nielsen A, Stragnell S, Jester P. Guide for reflection using the clinical judgment model. Journal of Nursing Education. 2009; 46: 513-516.

[19] Ashcraft A, Option L. Evaluation of the Lasater Clinical Judgment Rubric. Clinical Simulation in Nursing. 2009: 5(3): 129-155. https://doi.org/10.1016/j.ecns.2009.04.006

[20] Oueda M. Analytical Review for Models Related to Health Education. Faculty of Nursing. The University of Alexandria. 1999; 1-8, 13-35.

[21] Van Graan AC, Koen MP, Williams MJ. Clinical judgment in nursing: A conceptual analysis (Unpublished doctoral thesis). SA: North-West University, Potchefstroom Campus; 2014. 14-66 p.

[22] Niederhauser V, Gubrud-Howe PM, Magnussen L, et al. Creating Innovative Models of Clinical Nursing Education. Journal of Nursing Education. 2012; 51(11): 1-6. PMid: 23061436. https: //doi.org/10.3928/01484834-20121011-02

[23] Vitale E. Clinical teaching models for nursing practice: a review of literature. Professional Infermieristiche. 2015; 67(2): 117-124. 